\title{
Occlusion of peripheral pulmonary vascular bed in a baby with idiopathic persistent fetal circulation
}

\author{
SHEILA McKENZIE, ^ SHEILA G HAWORTH \\ From the Department of Paediatric Cardiology, Institute of Child Health, Guilford Street, London
}

SUMMARY A baby with idiopathic persistent fetal circulation died at 8 days of age despite treatment with tolazoline and maintenance of a normal acid base status. Detailed morphometric studies on the lungs showed muscularisation of the entire precapillary bed, with occlusion and loss of peripheral pulmonary arteries.

Babies with a normal heart and persistence of the fetal circulation are frequently referred to the cardiologist because they present with severe cyanosis in the absence of parenchymal lung disease. Persistence of the fetal circulation may be associated with birth asphyxia, polycythaemia, hypoglycaemia, ${ }^{1}$ and premature closure of the ductus arteriosus. ${ }^{2}$ Occasionally, however, no "trigger" factor can be identified. The present report concerns such an infant who died at 8 days, despite optimal medical management, because the peripheral pulmonary arterial bed was occluded by smooth muscle and swollen endothelial cells. The development of the pulmonary circulation was assessed by applying quantitative morphometric techniques to the injected and inflated lung. The structural changes found were more severe and extensive than those previously reported. ${ }^{34}$

\section{Case report}

A female infant was delivered normally at 39 weeks gestation, weighed $2.95 \mathrm{~kg}$, and was the third child of a 29-year-old mother, whose two previous babies were normal. The mother took chlordiazepoxide and promethazine throughout the first trimester. On the second day of life, the baby was transferred to The Hospital for Sick Children, Great Ormond Street, because she was cyanosed and had tachypnoea, tachycardia, and a soft apical systolic murmur. The chest radiograph was normal and showed no cardiac enlargement, normal pulmonary vascular markings, and no evidence of airways disease. The electrocardiogram, plasma electrolytes, and calcium and haemoglobin concentration were normal. Throughout the

* Dr Sheila McKenzie is supported by the National Fund for Research into Crippling Diseases. course of the illness the inspired oxygen concentration was adjusted to maintain an arterial oxygen tension greater than $40 \mathrm{mmHg}$, the arterial $\mathrm{pH}$ and $\mathrm{CO}_{2}$ tension being normal. On the second day of life, cardiac catheterisation showed a pulmonary arterial pressure of $75 / 45 \mathrm{mmHg}$, equal to the systemic arterial pressure. The pulmonary venous oxygen saturation was 98 per cent but oximetry showed a bidirectional shunt at atrial level and a right-to-left shunt across the ductus arteriosus, giving a postductal arterial oxygen saturation of 41 per cent. Treatment with tolazoline was started on the second day of life as an intravenous bolus of $1.5 \mathrm{mg} / \mathrm{kg}$ and continued until death as an infusion of $1 \mathrm{mg} / \mathrm{kg}$ per hour. The baby breathed spontaneously an inspired oxygen concentration of 80 to 100 per cent until the eighth day when she deteriorated rapidly. She died a few hours after assisted ventilation was started.

At necropsy, the ductus arteriosus was patent and large and the foramen ovale was also patent. The heart and great vessels were normal, including the size and position of the pulmonary veins.

\section{PREPARATION OF LUNG TISSUE AND}

TECHNIQUES OF ANALYSIS

After removing one block of tissue for study of $1 \mu \mathrm{m}$ sections, the pulmonary arteries were injected with a barium-sulphate gelatin mixture. It was impossible to inject the lungs at the customary constant infusion pressure of $100 \mathrm{~cm}$ of water. The lungs were therefore injected by hand and were more difficult to inject than any lungs previously studied in this laboratory, irrespective of age or disease. The fixed and inflated specimen was radiographed and its volume determined. From the injected specimen, 15 blocks of tissue were taken at random from both lungs for quantitative morphometric analysis and for serial 
sectioning. The uninjected tissue was embedded in Epon and $1 \mu \mathrm{m}$ sections were stained with toluidine blue.

The branching pattern of the preacinar ${ }^{\star}$ arteries was assessed on the radiograph and that of the intra-acinar arteries, microscopically, by serial reconstruction. Microscopically, by applying quantitative morphometric techniques the wall structure, size, and number of peripheral pulmonary arteries throughout the lungs were determined. Arterial muscularity was assessed by measuring medial thickness of more than 100 arteries less than $1000 \mu \mathrm{m}$ in diameter, relating this to the external diameter, and calculating the percentage arterial medial thickness. Peripheral pulmonary arteries can be identified according to the airway they are accompanying, and the size of vessel and type of wall structure (non-muscular, partially muscular, or entirely muscular) were assessed for the small preacinar and intra-acinar arteries. The distribution of muscle in the peripheral arteries was also shown by serial reconstruction of a segmental arterial pathway, the size and wall structure of all arterial branches being traced. Arteries and alveoli were counted per unit area of lung and the alveolar/arterial ratio calculated. Total alveolar number was assessed and 20 radial alveolar counts determined.

\section{Results}

The external appearance and volume of the lungs was normal. The pre- and intra-acinar branching pattern, from the hilum to the alveolar wall, was normal. Radial alveolar counts were normal (4.5) and the total alveolar number was similar to that of three agematched controls.

\section{ARTERIAL MUSCULARITY}

Arterial muscularity was increased, as shown by an increase in percentage medial thickness in arteries which normally have a muscle coat. Percentage arterial medial thickness in arteries of 75 to $100 \mu \mathrm{m}$, for example, was $11 \cdot 7$, as compared with a normal value of 5.5 at this age. ${ }^{5}$ Muscularity also extended into smaller and more peripheral arteries than normal. Normally few arteries smaller than $75 \mu \mathrm{m}$ in diameter contain any muscle, but in this case all the small arteries were muscularised and percentage arterial medial thickness in these vessels even exceeded the normal fetal level. In addition, in the normal lung at this age the majority of arteries beyond terminal bronchiolar level are non-muscular, ${ }^{5}$ but in this infant 18.2 per cent of arteries were completely surrounded by a thick muscle coat and the remaining vessels were partially muscular. These features of increased muscularity were present throughout both lungs.

\footnotetext{
* An acinus is all the lung tissue distal to a terminal bronchiolus.
}

In the serial reconstruction of the peripheral arterial pathway, all branches showed a similar change in wall structure as the vessels proceeded towards the capillary bed (Fig. a-d). Within the alveolar walls the thick walled arteries, less than $30 \mu \mathrm{m}$ in diameter, ended abruptly as partially or totally occluded vessels in a network of fine capillary channels. No arteriovenous connections were found on serial reconstruction or inspection of the random sections. Many thin walled channels were seen within the alveolar walls and, when traced, joined distended veins which occupied a normal position in the connective tissue septa. The lymphatic channels were also distended. No evidence of thrombus formation was seen.

ARTERIAL SIZE AND NUMBER

On the necropsy arteriogram the lumen diameter of the preacinar arteries was at the lower limit of normal. Microscopical measurements showed that the intraacinar arteries were abnormally small. Arteries accompanying the respiratory bronchioli had a mean external diameter of $60.9 \mu \mathrm{m}$, smaller than that of the normal 3-day infant $(92 \cdot 7 \mu \mathrm{m})^{5}$ and only slightly larger than is found in a normal fetus at term $(51 \cdot 3$ to $52 \cdot 8 \mu \mathrm{m}){ }^{6}$ A reduction in number of arteries per unit area gave an alveolar/arterial ratio of 40 , as compared with the normal value of about 15 at this age (A A H Hislop, 1981 personal communication).

\section{Discussion}

This baby had the typical clinical features of persistence of the fetal circulation, without an identifiable precipitating factor. Her mother had not taken a drug known to be associated with an increase in pulmonary arterial smooth muscle, such as a prostaglandin synthetase inhibitor. ${ }^{7}$ The lungs were not hypoplastic, being of normal size with normal airway and preacinar arterial development.

The structural changes in this baby were more severe than those previously reported in infants dying with idiopathic persistence of fetal circulation. ${ }^{34}$ Not only was muscularity increased but, in addition, the intra-acinar arteries were reduced in size and number. In a previous study, the lungs of three babies were studied using the same techniques of injection and quantitative morphometric analysis. ${ }^{4}$ All three infants had a full complement of intra-acinar arteries and only one showed a reduction in intra-acinar arterial size and that at 3 months of age. In the present case, the thin walled, partially muscular and non-muscular segments of the precapillary bed were entirely replaced by thick walled vessels extending down to the capillary bed.

The thick walled alveolar wall arteries with an occluded lumen were indistinguishable from the 

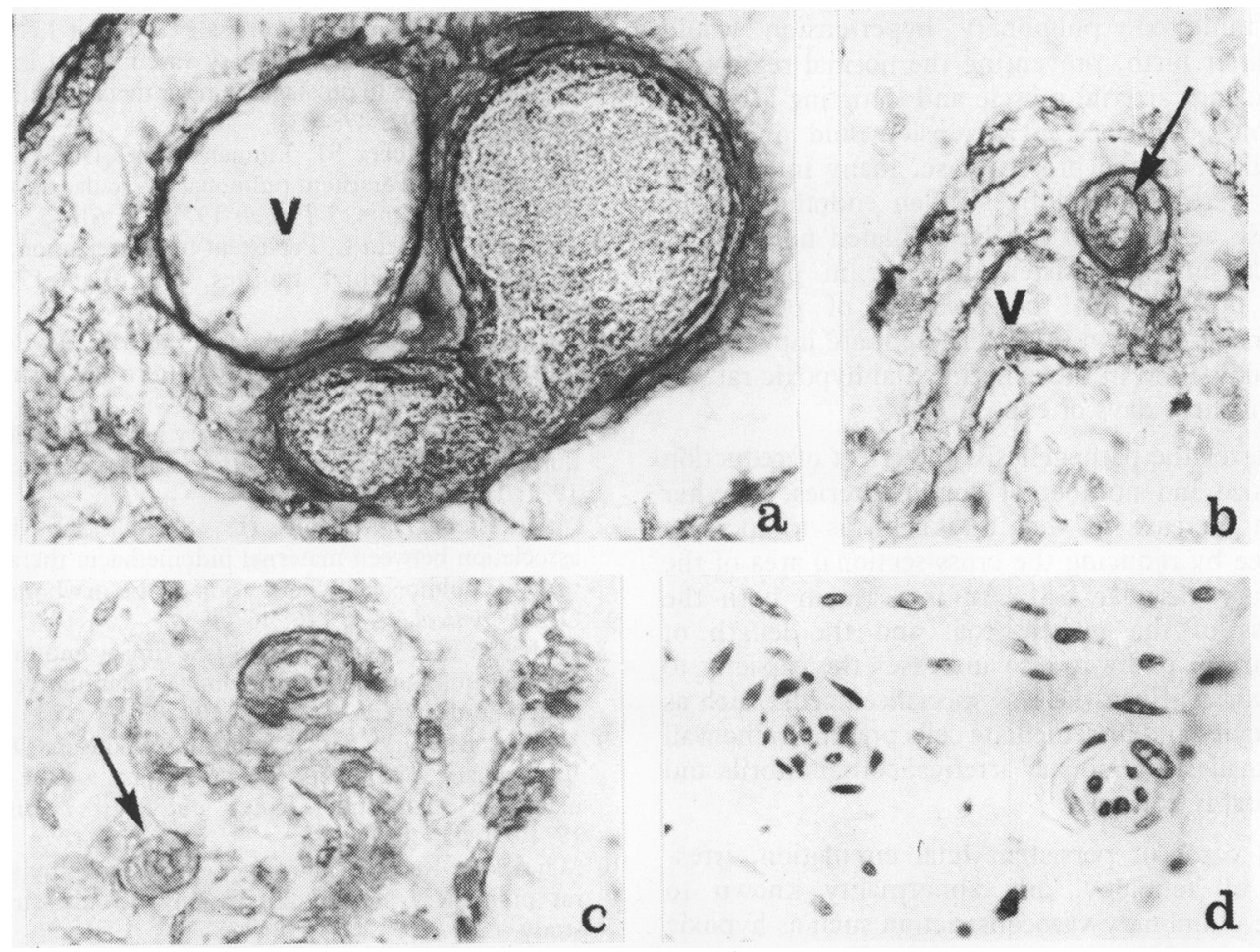

Fig. (a) Artery accompanying a terminal bronchiolus, filled with injection material, entirely surrounded by a layer of muscle. $V$, dilated vein. (Original magnification $\times 600$. Miller's elastic stain.) $(b)$ More peripheral alveolar duct artery showing the incomplete internal elastic lamina (arrow) of a partially muscular artery, the lumen occluded by cells. $V$, dilated vein. (Original magnification $\times 600$. Miller's elastic stain.) (c) “Ghost" artery (arrow) with no lumen. (Original magnification $\times 600$. Miller's elastic stain.) (d) Thin $(1 \mu \mathrm{m})$ section showing whorled appearance of a "ghost" artery, lumen occluded by endothelial cells. (Original magnification $\times 600$. Toluidine blue stain.)

"ghost" arteries described in primary pulmonary hypertension (non-thromboembolic) in adults. ${ }^{8}$ Electron microscopical examination of "ghost" arteries in a case of primary pulmonary hypertension showed a circumferential arrangement of reticulin, collagen, fibroblasts, and relatively undifferentiated smooth muscle cells, called pericytes, around a lumen partially or totally occluded by swollen endothelial cells. ${ }^{9}$ Similar ultrastructural features were found in the non-muscular alveolar wall arteries of hypoxic rats, where pre-existing cells, the pericytes, differentiated to form "new" muscle. ${ }^{10}$ The newborn lung probably produces an abnormal amount of muscle by the same process of cell differentiation. It appears that in pulmonary hypertension, whatever the cause, the first structural change occurs in the normally nonmuscular arteries lying immediately proximal to the capillary bed. In infants with congenital heart disease it is these vessels which first show an increase in wall thickness. ${ }^{11}$
In the present case, the insult to pulmonary vascular development probably occurred in late fetal life, at or after birth, because the structural abnormality was restricted to the intra-acinar arteries which develop in late fetal life and after birth. ${ }^{5}$ The magnitude of pulmonary vascular change suggests that at least some of the increase in muscle developed before birth. In addition, the intra-acinar arteries might have failed to grow and multiply normally in utero. Alternatively, recent studies indicate that the lung might have been structurally normal at birth, but had failed to adapt normally to extrauterine life. ${ }^{12}$ In the pig, the first structural change seen five minutes after birth is the dilatation and recruitment of non-muscular and partially muscular arteries in the precapillary bed. The endothelial cells become less prominent and muscle regresses in the larger arteries, a slower process occurring during the first week of life.

If, for any reason, any or all of these processes were 
to be inhibited, pulmonary hypertension would persist after birth, preventing the normal regression of pulmonary arterial muscle and initiating a vicious circle of pulmonary hypertension and increased muscularity. In the present case, many intra-acinar arteries were occluded by swollen endothelial cells and these vessels may not have dilated normally at birth, causing a persistent increase in pulmonary arterial pressure. In the presence of pulmonary hypertension, pericytes can differentiate into muscle cells rapidly, and in the experimental hypoxic rat, do so within three days of exposure. ${ }^{13}$

Whatever the pathogenesis, the effect of reduction in the size and number of patent arteries, together with an increase in wall thickness, is to increase resistance by reducing the cross-sectional area of the pulmonary vascular bed. An increase in both the thickness of the muscle coat and the length of muscularised pathway also increases the capacity to vasoconstrict. Even the less specialised cells, such as the pericytes and intermediate cells present in the wall of the smallest pulmonary arteries, contain fibrils and can probably constrict. ${ }^{10}$

In all cases of persistent fetal circulation, irrespective of aetiology, any abnormality known to promote pulmonary vasoconstriction such as hypoxia and acidosis needs prompt treatment. The response to pulmonary vasodilators is variable and in the present case infusion of tolazoline had no effect on the malignant progression of the disease. Tolazoline, however, may act chiefly on the smooth muscle cells and in this case may have had relatively little effect on arteries at alveolar duct and wall level which were occluded by swollen endothelial cells. If, in such cases, the first structural change is swelling of the endothelial cells in the small precapillary arteries, increase in muscle being a secondary phenomenon, tolazoline may not always have the desired effect.

\section{References}

1 Gersony WM. Persistence of the fetal circulation. A commentary. F Pediatr 1973; 82: 1103-6.
2 Levin DL, Fixler DE, Morriss FC, Tyson J. Morphologic analysis of the pulmonary vascular bed in infants exposed in utero to prostaglandin synthetase inhibitors. $\mathcal{F}$ Pediatr 1978; 92: 478-83.

3 Siassi B, Goldberg SJ, Emmanouilides GC, Higashino SM, Lewis E. Persistent pulmonary vascular obstruction in newborn infants. $f$ Pediatr 1971; 78: 610-5.

4 Haworth SG, Reid L. Persistent fetal circulation. Newly recognized structural features. $\mathcal{F}$ Pediatr 1976; 88: 614-20.

5 Hislop A, Reid L. Pulmonary arterial development during childhood: branching pattern and structure. Thorax 1973; 28: 129-35.

6 Hislop A, Reid L. Intrapulmonary arterial development during fetal life-branching pattern and structure. $\mathcal{F}$ Anat 1972; 113: 35-48.

7 Manchester D, Margolis HS, Sheldon RE. Possible association between maternal indomethacin therapy and primary pulmonary hypertension of the newborn. $A m \mathcal{F}$ Obstet Gynecol 1975; 126: 467-9.

8 Anderson EG, Simon G, Reid L. Primary and thromboembolic pulmonary hypertension: a quantitative pathological study. F Pathol 1973; 110: 273-93.

9 Meyrick B, Clarke SW, Symons C, Woodgate DJ, Reid L. Primary pulmonary hypertension: a case report including electronmicroscopic study. $\mathrm{Br} \mathcal{F}$ Dis Chest 1974; 68: 11-20.

10 Meyrick B, Reid L. The effect of continued hypoxia on rat pulmonary arterial circulation. An ultrastructural study. Lab Invest 1978; 38: 188-200.

11 Rabinovitch M, Haworth SG, Castaneda AR, Nadas AS, Reid LM. Lung biopsy in congenital heart disease: a morphometric approach to pulmonary vascular disease. Circulation 1978; 58: 1107-22.

12 Haworth SG, Hislop AA. Adaptation of the pulmonary circulation to extrauterine life in the pig and its relevance to the human infant. Cardiovasc Res 1981; 15: 108-19.

13 Hislop A, Reid L. New findings in pulmonary arteries of rats with hypoxia-induced pulmonary hypertension. $\mathrm{BrF}$ Exp Pathol 1976; 57: 542-54.

Requests for reprints to Dr S G Haworth, Thoracic Unit, The Hospital for Sick Children, Great Ormond Street, London WCIN 3JH. 